\title{
aniki
}

Revista Portuguesa da Imagem em Movimento

Portuguese Journal of the Moving Image

\section{Diapomontajes: Audiovisuales de transición en el Uruguay de mediados de 1980}

\author{
Mariel Balás \\ Universidad de la República, Montevideo, Uruguay \\ marbalas@gmail.com \\ https://orcid.org/0000-0002-6590-7127
}

RESUMEN La intención de este artículo es abordar el uso del diapomontaje como tecnología de transición entre la cinta fotoquímica y la cinta de video. Para ello se pondrán en diálogo dos realizaciones de mediados de 1980 que corresponden a dos productoras uruguayas contemporáneas. Se trata de Destituidos (1984) del Centro de Medios Audiovisuales (CEMA) y La gesta de una conciencia (1985) de la productora Imágenes. El tipo de audiovisual aquí presentado como medio de expresión comunicacional y cultural fue muy utilizado durante la dictadura uruguaya que tuvo lugar entre 1973 y 1985. Se trata de un tipo de realización audiovisual que ha sido poco abordado por la academia. A partir del acercamiento a la técnica del diaporama y de la combinación de los soportes que hacen posible la experiencia audiovisual (fotoquímico de la diapositiva y magnética de la cinta de audio), se analizará la producción de contenidos, el montaje y la puesta en escena en un caso y otro.

PALABRAS CLAVE Diapomontaje; transición; archivo; video; audiovisual uruguayo; diapositivas.

\section{Introducción}

En este artículo el protagonista es el diapomontaje, una técnica conocida también como diaporama o "audiovisual" como comúnmente era nombrado por los realizadores para distinguirlo de la película cinematográfica. ${ }^{1}$ En Uruguay estos audiovisuales (que combinaban diapositivas y banda sonora) tuvieron su auge a partir de mediados de los setenta y primeros años de los ochenta, es decir en pleno período

\footnotetext{
${ }^{1}$ Interesa en este punto mencionar el trabajo de Alfonso Palazón (2001) quien identifica el diaporama como una proyección que combinaba una compleja serie de equipos e indistintamente se denominaba multivisión. Como se verá, este tipo de exhibiciones que combinaban varios proyectores es el utilizado para el caso de La gesta de una conciencia (Jacob y Tournier, 1985).
} 
dictatorial (1973-1985). Su uso se fue abandonando progresivamente con la incorporación de la tecnología video a mediados de los ochenta. Macarena Fernández Puig, en su investigación recabó por lo menos cuarenta y tres diapomontajes realizados entre 1975 y 1981 (Fernández Puig 2015). A este listado se suman, los veinticuatro audiovisuales producidos con esta técnica por el Centro de Medios Audiovisuales.

En su artículo, Fernández Puig (2015) destaca que mayormente se trataba de producciones de aficionados que se agrupaban para concretar proyectos colectivos. Las temáticas refieren a diversos asuntos como la construcción de una cooperativa de ayuda mutua (Italo Siga y Cristina Fernández, 1976) o ciudades italianas (Florencia y Venecia: un diario de renacimiento de José María Varela y Florencia histórica y mágica del profesor Alfonso Lambías de Acevedo, ambas de 1976). La capital uruguaya también recibió particular atención, lo que se constata a partir de títulos como: Montevideo Antiguo (Miguel Bategazzore, 1975), Ciudad Vieja (Diego Abal, Julián Murguía, 1976), o Tristán Narvaja (Alejandro y Rafael Abal, 1978), que registra la feria que, desde principios del siglo pasado, se ubica sobre esa calle y sus aledaños ofreciendo una amplia variedad de productos, desde curiosidades hasta frutas de estación. Los diapomontajes eran proyectados principalmente en concursos organizados por entidades como Cine Club del Uruguay en colaboración con el Instituto Italiano de Cultura y por la Alianza Francesa, así como en festivales, ferias y eventos culturales (Fernández Puig 2015). Además del uso por parte de realizadores independientes, Fernández Puig recupera la producción de diaporamas para publicidad, principalmente de la mano de la empresa Varela Audiovisuales y como medio de apoyo a instancias educativas. ${ }^{2}$

Si bien Beatriz Tadeo Fuica y Julieta Keldjian (2020) realizaron una investigación en la que establecen que el Super $8 \mathrm{~mm}$ en Uruguay fue la tecnología de transición hacia el video, teniendo en cuenta los datos presentados aquí, es decir, la significativa cantidad de audiovisuales realizados durante el periodo mencionado, este artículo propone que el diapomontaje, también tuvo ese lugar transicional. En este sentido interesan las palabras de Paola Margulis acerca de la complejidad que implica abordar el concepto de transición en virtud de las realizaciones

\footnotetext{
${ }^{2}$ Una entidad de formación que me interesa destacar fue la producción y uso de los diapomontajes por parte del Departamento de Medios Técnicos (DMTC) de la Universidad de la República. Para conocer más acerca del DMTC, ver revistas Notas del Cine Uruguayo en el Archivo General de la Udelar, fondo Instituto de Cinematografía de la Universidad de la República (ICUR), caja 7. Para el caso de producciones independientes se consultó una sistematización inédita realizada por la investigadora Macarena Fernández Puig, quien la compartió gentilmente.
} 
audiovisuales y, por lo tanto, de la necesidad de aplicar el término en plural:

(...) optamos por hablar de transiciones y no de transición, debido a que los procesos de cambio son múltiples y complejos, al articular dimensiones políticas, culturales, tecnológicas y estéticas. Como es sabido, las transformaciones en los formatos de producción generan distintos tránsitos en los modos de ver y producir imágenes de la realidad. (Margulis 2020, 26)

Para observar el uso de la misma técnica, pero con particulares modos de producción y contextos de exhibición me detendré en los diapomontajes de dos colectivos distintos. Se trata de Destituidos (1984), realizado por el Centro de Medios Audiovisuales y de La gesta de una conciencia (1985) de la productora Imágenes. ${ }^{3}$

Para concretar esta investigación, además del contacto con el archivo de diapomontajes del CEMA, fueron fundamentales las entrevistas con Diego Abal, realizador amateur, y con Trygve Rasmussen y Laura Canoura, quienes dentro del CEMA se dedicaron al área de fotografía y revelado y al diseño gráfico, la edición y la locución respectivamente. Por su parte, a partir del diálogo con Mario Jacob, uno de los fundadores de la productora Imágenes, fue posible conocer detalles sobre la realización de uno de los diapomontajes objeto de este artículo y tomar contacto con su versión digital.

\section{En qué consiste un diapomontaje}

Antes de profundizar en los dos casos puntuales considero pertinente explicar qué es un diapomontaje. Se trata de una técnica que consistía en proyectar diapositivas al ritmo de una banda sonora integrada por locución, música y efectos sonoros. En los años setenta la diapositiva era una forma de registro muy utilizada por la clase media uruguaya para registrar viajes y eventos sociales relevantes (casamientos, cumpleaños, aniversarios) que luego eran compartidos con personas

\footnotetext{
${ }^{3}$ Quedará para futuras instancias abordar los antecedentes de esta técnica, para lo cual es una referencia ineludible el trabajo de Georgina Torello (2018), en particular el análisis de las proyecciones luminosas y la relevancia que tenía la exhibición de imágenes fijas en el contexto más amplio de programas cinematográficos (77-110). Siguiendo su línea de investigación interesa reponer los conceptos presentados por André Gaudreault y Philippe Marion (2005) y la alusión al doble nacimiento por la que los autores plantean que debe transitar un medio para lograr su institucionalización. Será pertinente también analizar la construcción de los relatos, así como la resignificación de la unidad fotográfica en función del sonido.
} 
del entorno más cercano, familia y amigos. La calidad que brindaba la imagen resultante del soporte fotoquímico y la posibilidad de visionado en un espacio con una luminosidad adecuada, hacía que la proyección fuera una experiencia de particular disfrute colectivo (comunicación personal con D. Abal, 2019). Pero en estos casos no había una banda sonora, la información complementaria era brindada por los relatos de las personas que usualmente habían protagonizado los instantes registrados. Entonces, entra así una de las principales diferencias entre la proyección casera de diapositivas y el diapomontaje. Junto con la intención creativa de generar un relato audiovisual, además de brindarle una determinada secuencialidad a las imágenes fijas, era preciso sincronizarlas con grabaciones sonoras que las acompañaran y que, de alguna manera, les marcara el ritmo de la proyección, variando el tiempo de permanencia de una imagen y otra. Para la captura de las imágenes se utilizaba un rollo de película fotoquímica de $35 \mathrm{~mm}$ cuya principal diferencia con el rollo de negativo fotográfico radicaba en el revelado, ya que, en esta etapa del proceso en lugar de negativos, se obtenía directamente la imagen en positivo. Luego se cortaban los fotogramas de la tira, se montaban en los soportes, o marcos y se determinaba un orden de acuerdo a un guion preestablecido que, en determinadas circunstancias, se adaptaba al público presente (comunicación personal con T. Rasmussen, 2018). La grabación del sonido requería algunas especificidades técnicas: comúnmente se realizaba en un estudio y se utilizaba una cinta de carrete abierto en la que se incorporaban los testimonios, las locuciones, los efectos sonoros y la música. Luego se copiaba a una cinta de casete de audio para simplificar su reproducción.

La puesta en funcionamiento de estos audiovisuales implicaba contar con varios elementos que debían necesariamente sincronizarse y funcionar: diapositivas colocadas en los carretes de uno o más proyectores y equipos reproductores de casetes de audio. A su vez, las potenciales fallas técnicas de su puesta en escena (quemarse la luz del proyector, trancarse una diapositiva o colocarla de manera incorrecta, proyectándose en la pantalla una imagen invertida tanto horizontal como verticalmente, así como dejar de funcionar la sincronización entre proyectores o el equipo de reproducción de sonido) generaba gran presión en los operadores. Si bien existía un guion y un determinado orden de las imágenes que acompañaba una sonorización, la duración de la exhibición, incluso de la disposición de las diapositivas, podía variar según el público. También el motivo o el 
contexto de la proyección, podría generar que fuera necesario agregar o quitar diapositivas, variar el tiempo de exhibición de cada imagen o incluso detener la proyección para iniciar un debate (comunicación personal con D. Abal, 2019). Mirar un diaporama implicaba, por lo tanto, estar en el lugar, compartir el espacio y el tiempo de esa proyección, junto con el accionar de los proyectores y la sincronización de los reproductores de audio, en su contexto de exhibición, el diapomontaje constituía un acto performativo.

\section{Uruguay de los ochenta y la producción de audiovisuales}

Los dos casos de estudio se insertan en un particular escenario político del país. En 1980 tuvo lugar en Uruguay un plebiscito promovido por los propios militares en el cual la población se manifestó en contra de la continuidad del régimen dictatorial instalado en el país desde 1973. Esta postura se reforzaría en noviembre de ese mismo año, cuando en las elecciones internas de los partidos habilitados ganaran los grupos opositores a la dictadura. Tras dichas instancias y durante el período de transición, muchas organizaciones continuaron reuniéndose y produciendo en clandestinidad, buscaron la manera de eludir la opresión, de denunciar no sólo las violaciones a los derechos humanos y el lugar de los sujetos en ese contexto represivo, sino también la situación del país y su realidad en cuanto a desempleo y endeudamiento. ${ }^{4}$

En ese contexto político y en plena crisis económica, paulatinamente se fue abriendo un espacio a distintas manifestaciones culturales. En ese escenario, hacia 1982 se constituyó el Centro de Medios Audiovisuales (CEMA). Fundado por Esteban Schroeder, Alejandro Barreiro y Eduardo Casanova, agrupó a jóvenes con afinidades artísticas, en su mayoría fotógrafos que de manera aficionada o profesional registraron distintas manifestaciones culturales de los últimos años de dictadura cívico militar. Se conformó como un colectivo de comunicación independiente con un objetivo claro, “en un país que no puede reconocerse en imágenes propias, nos proponemos ser gestores de una práctica audiovisual renovada" (Catálogo CEMA, 1990). Siguiendo esa línea organizaron un plan que, tras presentarlo en distintas instituciones, obtuvo el apoyo de diversos organismos internacionales

\footnotetext{
${ }^{4}$ Se utiliza el término transición teniendo en cuenta la periodización establecida por el politólogo Luis Eduardo González, tomado de Caetano y Rilla (1998).
} 
como la Agencia Canadiense para el Desarrollo Internacional de Canadá (ACDI) y de Diakonía de Suecia. En este sentido resultan interesantes, por sus afinidades con el caso uruguayo, las palabras del investigador Germán Liñero al referirse al surgimiento de espacios dedicados a la cultura en los inicios de los ochenta:

\begin{abstract}
Si algo tuvo de especial la primera mitad de la década de los ochenta fue el florecimiento de decenas de iniciativas independientes destinadas a ampliar los espacios de creación y difusión cultural como respuesta a la inexistencia de espacios de participación en los medios oficiales. (...). Aparecen (...) diversos lugares amparados por universidades, organismos no gubernamentales, sindicatos, la Iglesia católica o los servicios culturales de ciertas embajadas que promovieron programas de trabajo en el ámbito cultural, haciéndose cargo de las evidentes ausencias de una política cultural democrática y pluralista en nuestro país. (Liñero 2010, 90)
\end{abstract}

De forma similar, además de ofrecer servicios de audio y diseño gráfico, en CEMA se editaban diapomontajes. La utilización de esta técnica se debió básicamente a dos aspectos. Por una parte, el grupo estaba conformado en su mayoría por aficionados a la fotografía. Hacia finales de 1970, Alejandro Barreiro y Esteban Schroeder, tenían un emprendimiento fotográfico, Estudio Épocas, y contaban con un laboratorio de revelado que luego pasaría a formar parte del CEMA (comunicación personal con E. Schroeder, 2015). La fotografía, por lo tanto, era el lenguaje "natural" de sus integrantes. Entre los cientos de registros fotográficos que nutrían el banco de imágenes del CEMA, había un gran aporte de tiras de negativos y diapositivas muchas de ellas pertenecientes a la labor de Esteban Schroeder, que se había dedicado a registrar actuaciones teatrales y musicales en distintos escenarios montevideanos (comunicación personal con E. Schroeder, 2015). ${ }^{5}$ El otro motivo fundamental para el uso de la técnica era que, en comparación con los costosos procesos de revelado de película, esta era mucho más accesible (comunicación personal con L. Canoura, 2015).

\footnotetext{
5 Existen, entre otros, registros fotográficos de presentaciones teatrales como el caso de "Yetatore" en el Centro Gallego (fechada en 1977), de la obra "Emigrados" en el Teatro Circular, de la "Lección de anatomía” en el Stella D’Italia, ambas de 1980. Incluso la entrega de los premios Florencio de 1982 en el Teatro Solís. De la escena musical hay varios registros desde un ensayo del cantante argentino León Gieco en la Sala Verdi en 1979, hasta varios rollos destinados a actuaciones de grupos musicales uruguayos como "Canciones para no dormir la siesta" (1980), "Rumbo", "Los que iban cantando" y de la presentación del músico uruguayo Ruben Rada en el teatro Miami en 1981 (AGU, CEMA, documentos donados por Miguel Ángel Olivera, en proceso de inspección e ingreso de datos).
} 
Las solicitudes de diapomontajes llegaban al CEMA a pedido de organizaciones sociales como el Movimiento de Erradicación de la Vivienda Insalubre Rural (MEVIR), el Centro Interdisciplinario de Estudios sobre Desarrollo (CIEDUR) y organismos internacionales como el Centro Latinoamericano de Economía Humana (CLAEH) o el Fondo de las Naciones Unidas para la Infancia (UNICEF), entre otros. ${ }^{6}$ Tras la proyección era habitual que se abriera un espacio para discutir las diferentes temáticas abordadas: derechos humanos, situación de la mujer, medio ambiente y otros asuntos de interés social. El procedimiento implicaba la redacción de un guion y la posterior selección del banco de imágenes o la toma fotográfica, para darle contenido visual al trabajo. En las instalaciones del CEMA se contaba con un estudio de sonido y un laboratorio para concretar el procesamiento fotoquímico. Usualmente estas tareas estaban a cargo de José Aprile y Trygve Rasmussen, respectivamente.

Según los equipos con los que contara la organización, se entregaba el material para ser dispuesto en uno o más proyectores. Si estas tenían la opción de utilizar dos proyectores y un equipamiento que permitiera el fundido de las imágenes, se incluían dos juegos de diapositivas numeradas como secuencias A y B. De esa manera el audiovisual cobraba cierto dinamismo al lograr fusionar dos imágenes, pero usualmente, se ordenaban las diapositivas para un solo proyector (comunicación personal con L. Canoura, 2015).

A modo de ejemplo abordaré el caso de Destituidos (1984), que formó parte de una trilogía que realizó CEMA bajo el nombre de Testimonios. ${ }^{7}$ El objetivo de esta serie era denunciar las distintas formas que asumió la violación a los derechos humanos en el país a partir de 1968 y, más crudamente, durante la dictadura que se instaló en 1973. Se propuso aportar a la difusión y promoción de una conciencia crítica y acompañar la creación de ámbitos de participación ciudadana capaces de intercambiar y debatir sobre la situación de los destituidos en el país. La serie Testimonios estaba integrada por los siguientes títulos: Derechos humanos, donde, a través de relatos y cifras, se ilustraba el exilio, la prisión, la tortura y la desaparición forzada en Uruguay; Por un paisito sin exclusiones, que registraba la llegada de los niños que vinieron desde el exilio a pasar las fiestas de fin de año con sus

\footnotetext{
${ }^{6}$ MOVIDE, programa conjunto (c. 1983); Un día (1984, CIEDUR); Industria (1985, CIEDUR); Hay un niño en la calle (1983, Claeh-UNICEF).

${ }^{7}$ Es posible ver Destituidos en línea: https://www.youtube.com/watch?v=7NfTPV80Whs
} 
familiares en diciembre de $1983,{ }^{8}$ y Destituidos. Este unitario de 12 minutos de duración, tal como su nombre indica, denunciaba la separación de sus cargos de miles de funcionarios públicos por motivos ideológicos y político-partidarios. Esta medida represiva afectó a varios sectores de la sociedad y fue un mecanismo más de persecución política de la dictadura uruguaya.

En términos de contenido, el audiovisual se compone de fotografías que fueron seleccionadas del banco de imágenes del CEMA o especialmente tomadas para acompañar la banda sonora integrada por música, efectos sonoros, locución y testimonios. Al inicio se suceden imágenes de las fachadas de distintos organismos públicos, intercaladas con distintas personas en plazas y calles y, paulatinamente, la música de tango es invadida por el sonido de una máquina de escribir. En una imagen se lee la portada del diario El País que anuncia la disolución de las cámaras, al son de un redoblante. La primera voz que se escucha es el testimonio de quien fuera inspectora del juzgado de menores, destituida el primero de agosto de 1977. Cada vez que se incluye un testimonio, se identifica a la persona con una fotografía. La voz del locutor informa que fueron diez mil personas destituidas, dato al que agrega que implicó la mayor cifra de funcionarios perseguidos por las dictaduras instaladas en el Cono Sur. A través del acto institucional número 7 , los funcionarios eran clasificados en categorías $a, b \mathrm{y} c$, con lo cual la población quedaba dividida en "buenos o malos orientales" (orientales es otra forma de llamar a los uruguayos). El locutor dice: "Ese abecedario del terror creó exiliados en su propio país, desterrados en su misma tierra". En el diapomontaje se expresa que, para finales de 1983, los destituidos se sumaron a la movilización popular y que hacia enero de 1984 había treinta y dos sectores de organismos públicos "representados en el movimiento naciente". En el audiovisual se alude al acto del primero de mayo de 1984 y concluye con la lectura del primer artículo del Proyecto de Ley de reparación: “todas las personas que prestaban funciones en organismos estatales o paraestatales y que a partir de junio de 1968 fueron separados de sus cargos y funciones por motivos ideológicos, serán inmediatamente reincorporadas”. Los compases de tango cierran el diapomontaje.

Salvo por el logo del CEMA que aparece al final, el audiovisual no tiene créditos iniciales ni finales, por lo tanto, se desconoce el origen que

\footnotetext{
${ }^{8}$ Se trató de un registro realizado por un colectivo de fotógrafos entre los cuales se encuentran Lilián Castro, Trygve Rasmunsen y Nelson Wainstein.
} 
motivó su producción, ni quienes participaron de las tomas fotográficas ni de la edición. Únicamente es posible distinguir la voz de Miguel Ángel Olivera quien se incorporó a la productora hacia 1984, una vez que recuperó su libertad, tras largos años de prisión por motivos políticos. A mediados de 1985, CEMA logró importar equipamiento para producir en cinta de video U-matic por lo tanto abandonaron paulatinamente el diapomontaje por el uso de este nuevo medio audiovisual. $^{9}$

Imágenes fue otra productora emblemática del periodo, fundada en 1985 a iniciativa de un grupo de cineastas que retornaron al Uruguay una vez recuperada la democracia. Inicialmente estuvo integrada por Mario Jacob, Walter Tournier y Victoria Pérez. Posteriormente se integraron Hilary Sandison, Daniel Márquez, José María Ciganda, Aranzazú Elola, Bárbara Álvarez, entre otros (González Dambrauskas 2020). ${ }^{10}$ En los años previos al golpe de Estado dos de sus integrantes, Jacob y Tournier, formaban parte de la Cinemateca del Tercer Mundo (C3M) cuya producción de contenido político y militante, era registrada y editada en películas $16 \mathrm{~mm}$. Perseguidos por la dictadura militar, se exiliaron en Perú desde donde desempeñaron diversas actividades vinculadas a la producción cinematográfica. ${ }^{11} \mathrm{Al}$ regresar a Uruguay se propusieron continuar con la realización audiovisual. A través de Sergio Villaverde, con quien Tournier había filmado en 1973 la película Una epidemia de Sarampión, recibieron la primera solicitud por parte del Sindicato Médico. ${ }^{12}$ Se trataba de generar un mediometraje para celebrar un triple aniversario, los setenta años de la Asociación de Estudiantes de Medicina, los sesenta y cinco de la fundación del Sindicato Médico del Uruguay (SMU) y los cincuenta del Centro de Asistencia, (CASMU). Al no contar con recursos suficientes para filmar en película fotoquímica y tampoco con equipamiento de video, recurrieron a un formato posible, la proyección con diapositivas. Por lo tanto, La gesta de una conciencia (1985) fue el primer trabajo

\footnotetext{
${ }^{9}$ Para profundizar en la producción del video del CEMA entre 1986 y 1995 ver Tadeo Fuica, y Balás (2016); Tadeo Fuica (2017); Balás (2020); y Balás (2018).

${ }^{10}$ Para profundizar sobre la productora Imágenes ver González Dambrauskas (2020) y Tadeo Fuica (2017).

${ }^{11}$ Para profundizar en las producciones realizadas por los integrantes de la C3M ver Lacruz (2016); Villaça (2012); y Jacob (1997).

${ }^{12}$ En la filmación Fray Bentos: Una epidemia de Sarampión participó también Mario Handler, quien no pudo acompañar la edición final debido a su exilio por razones políticas. Es posible ver la película y contar con más información de este film en la base de datos del LAPA-AGU-Udelar en línea en el siguiente enlace: https://archivosdocumentales.udelar.edu.uy/index.php/fray-bentos-una-epidemia-de-sarampion (visitado: 18/10/2021).
} 
audiovisual de Imágenes. ${ }^{13}$ Optaron por realizar un documental que presentara el contexto histórico de los primeros treinta y cinco años del siglo pasado. A través de un recorrido por los aspectos socioeconómicos, políticos y culturales del país enmarcaron el surgimiento de la Asociación estudiantil, del sindicato y del sanatorio en permanente relación con los principales hechos mundiales. La investigación, a cargo de Alicia Artigas y Aranzazú Elola, llevó varios meses. Las imágenes que componen el audiovisual son en su totalidad fotografías tomadas de distintos archivos. Recabaron imágenes del propio archivo del SMU, pero también lograron acceder a revistas en la Biblioteca Nacional, al fondo de fotografías de la Intendencia de Montevideo (actual Centro de Fotografía) y a las placas de vidrio conservadas en el Archivo de la Imagen y la Palabra del Sodre (entidad estatal). Tournier se encargó de las tomas fotográficas, y la coordinación de toda la tarea estuvo a cargo de Villaverde. El sonido fue grabado en las instalaciones de CEMA en donde contaron con la colaboración de Apriles (comunicación personal con M. Jacob, 2017).

Siguiendo las palabras de Alfonso Palazón, la proyección funcionó como un evento de "multivisión":

La fuerte tensión visual para guiar al espectador en el recorrido de la mirada por la pantalla desplaza zonas significativas de la imagen. El juego con los marcos acentúa la fragmentación de la pantalla como elemento discursivo de la representación de esa tensión visual (...). La imagen fotográfica acepta este nuevo estilo de imagen múltiple invitando a la contemplación de las diferentes formas de la imagen. La relación del espectador y la imagen se establece en cómo se organizan todos los elementos del diaporama." (Palazón 2001, 34-35)

Para lograr este visionado, el montaje de la proyección requirió de tres pares de proyectores, es decir seis equipos en total que debían ser todos de igual marca para que tuvieran la misma luminosidad con el fin de garantizar una proyección exitosa. Este complejo sistema de proyección permitió dividir una imagen en tres, visionar tres imágenes diferentes en simultáneo o de manera sucesiva, dejando en negro alguno de los espacios o completando toda la pantalla. Cada imagen, o conjunto de imágenes, se proyectaba en sincronía con la cuidada banda sonora integrada por efectos sonoros y una musicalización acorde a

\footnotetext{
${ }^{13}$ Es posible ver La gesta de una conciencia en línea:

https://www.youtube.com/watch? $\mathrm{v}=0 \mathrm{xBDUlPthL8 \& t=1568s}$ (visitado: $18 / 10 / 2021$ ).
}

aniki A Pesquisa Histórica no Cinema Latino-americano | Historical Research in Latin-American Cinema 
cada período de la narración (música clásica, valses, tango, charlestón). La locución, a cargo de Béquer Puig, estaba elaborada para ser escuchada en un espacio donde no hubiera lugar a la distracción, es decir, como en este caso, una sala de teatro, pero también podría ser un cine.

El 16 de diciembre de 1985, en el semanario capitalino Brecha, el crítico Juan Carlo Capo expresaba sobre La gesta de una conciencia:

La elección de los documentos es original, reverberantes, el ritmo del audiovisual obtenido en base a esfumaturas, encadenados, divisiones de la pantalla, fluido, ágil (años locos, el cambio de cara de la ciudad) por momentos moroso y reflexivo (dictadura de Terra, suicidio de Brum) (...). (p. 22)

Con este audiovisual Jacob y Tournier lograron una recomposición histórica de Uruguay, no ajeno a la realidad global, que acompañaba y contextualizaba los tres aniversarios que motivaron la solicitud.

Esta única experiencia de Imágenes con el uso del diapomontaje presenta una serie de elementos que permiten contraponer modos de producción y de proyección con el caso del CEMA. En primer lugar, al ver La gesta de una conciencia, llama la atención el estilo de la grabación en video de las proyecciones, en lugar de ver un pase de imágenes, editadas al ritmo de la música y la locución en un formato pantalla de televisión 4:3 (como es el caso de visionado de los diapomontajes filmados por el CEMA), vemos la unión de tres imágenes que en su conjunto homologan una pantalla a una dimensión 16:9, es decir, una pantalla cinematográfica. Esta realización que dura casi media hora (28') fue pensada desde un inicio para ser proyectada en una pantalla que ellos mismos solicitaron confeccionar a la medida del lugar en donde sería exhibida, y que cubriera toda la "boca" del escenario principal del teatro El Galpón de Montevideo. Para la edición pensaron en distintas modalidades que hicieran una exhibición dinámica, para salir del "estatismo" que implicaba un diaporama convencional (comunicación personal con M. Jacob, 2017). Por esa razón hay diferentes usos de los tres espacios que en su conjunto emulan una pantalla cinematográfica. 

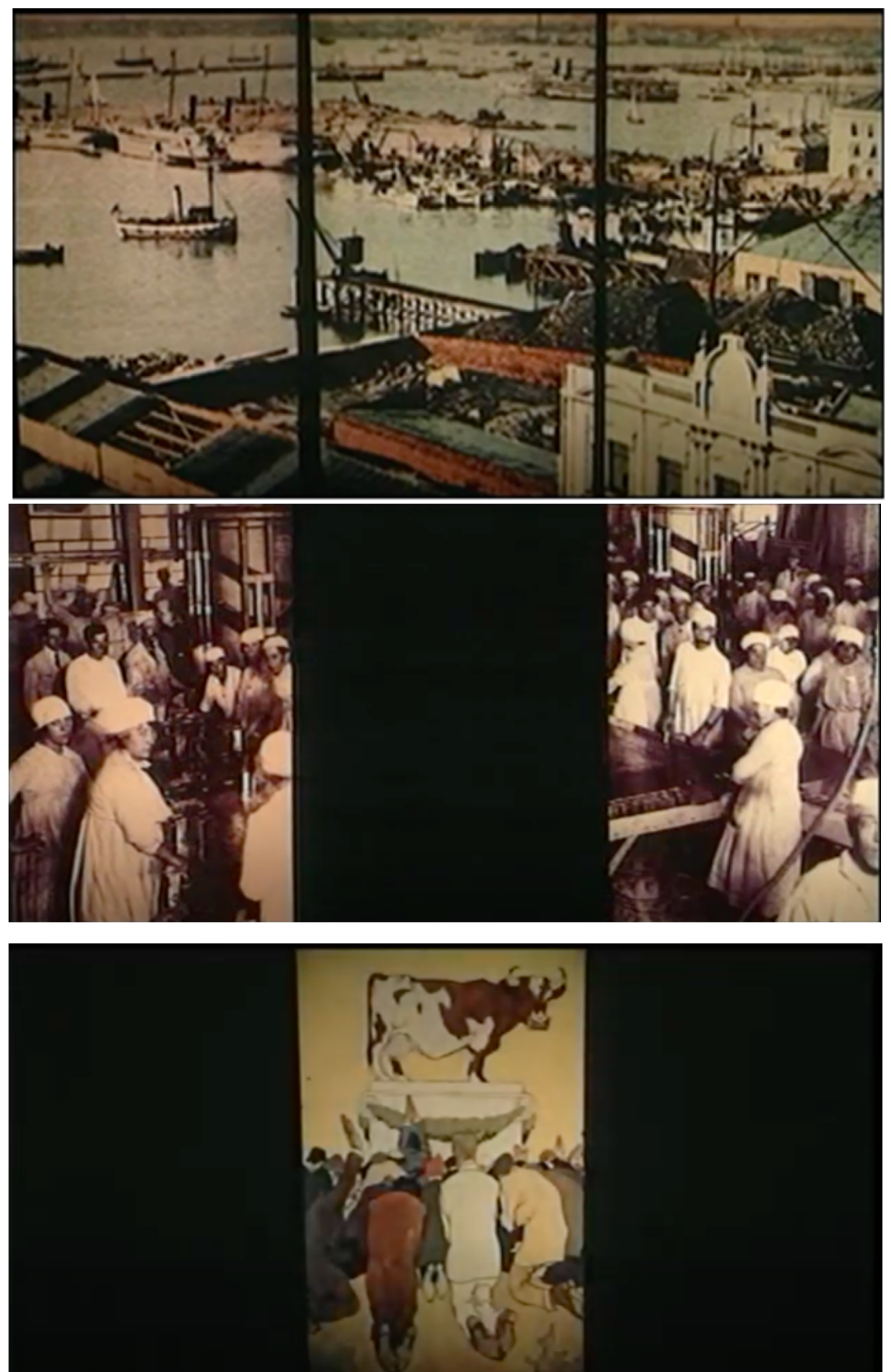

Imagen 1, 2 y 3: Capturas de pantalla del archivo digital del diapomontaje La gesta de una conciencia (Jacob y Tournier, 1985). | En línea: https://www.youtube.com/watch? $\mathrm{v}=0 \mathrm{xBDUlPthL} 8 \mathrm{~s}=1568 \mathrm{~s}$ (visitado: $18 / 10 / 2021$ ). Se distingue el uso de los tres pares de proyectores en el que cada par proyecta una misma 
imagen dividida en tres o está proyectando simultáneamente imágenes diferentes dejando espacios sin proyectar.

Tras esta primera y única experiencia con diapositivas, sus trabajos posteriores fueron utilizando la tecnología video tras la adquisición de equipamiento U-matic en 1986 (González Dambrauskas 2020).

\section{Los archivos y su acceso}

Tomar contacto con los archivos, y me refiero al contacto físico, tangible, permite reconocer lo hecho. También permite comprender los usos de determinadas herramientas en sus respectivos contextos políticos y económicos. La materialidad de los archivos audiovisuales es frágil. Por lo tanto, en este caso cobra especial interés el hecho de aplicar procesos de migración para que esos materiales estén disponibles digitalmente en sitios virtuales y garantizar su acceso en casos en que no es posible el contacto directo con los materiales. Pero también es imprescindible cuidar su integralidad, conservándolos y dejándolos disponibles para los investigadores futuros.

Tal como se vio la tecnología de producción y reproducción del diapomontaje es un híbrido, compuesto por la unidad fotográfica de la diapositiva y sus respectivos procesos fotoquímicos y la cinta magnética del carrete abierto o el casete de audio. Aquí se destaca un elemento clave a la hora del tratamiento integral de los componentes del diapomontaje de cara a la conservación. En este sentido si bien la diapositiva presenta por su composición gran estabilidad, la emulsión de los casetes de audio, integrados por partículas electro magnetizadas, tiene una durabilidad mucho menor. Se estima que mantiene su estabilidad entre veinte y treinta años en condiciones de temperatura y humedad controlada, lo cual resulta muy difícil de lograr en países con elevados índices de humedad y temperatura variable como Uruguay (International Association of Sound and Audiovisual ArchivesTechnical Committee 2005).

En el año 2011, en el marco de un proyecto de rescate del archivo de lo que fue la productora Centro de Medios Audiovisuales (CEMA), se estableció contacto con varias personas que habían integrado el colectivo. ${ }^{14}$ En uno de esos encuentros aparecieron cuatro casetes VHS.

\footnotetext{
${ }^{14}$ Para ampliar información sobre el proyecto de rescate, ver Tadeo Fuica y Balás (2016) y en particular sobre el archivo y su recomposición ver Balás y Tadeo Fuica (2020).
} 
El visionado de sus contenidos permitió conocer sus primeras realizaciones de diapomontaje. En 1990 los integrantes del CEMA decidieron proyectar y capturar los diaporamas con la tecnología video. Gracias a esa iniciativa se tomó contacto con doce audiovisuales, parte de una producción mucho más numerosa. En 2018 Miguel Ángel Olivera donó al Laboratorio de Preservación Audiovisual del Archivo General de la Universidad de la República (LAPA-AGU-UdelaR) varios materiales que aún conservaba de lo que había sido el archivo fotográfico del CEMA. En las cajas había veinticinco carpetas conteniendo el formato original de los diapomontajes, tal como eran arrendados a distintas organizaciones para su exhibición. Las carpetas, cuando estaban completas, contenían fundas con diapositivas, numeradas y ordenadas, un manual de uso, el guion y dos casetes de audio. Los casetes estaban rotulados con etiquetas en las que se leía "impulsos audibles" o "impulsos inaudibles". Esto indicaba que, según fuera el caso, podrían usarse con reproductores capaces de leer los impulsos inaudibles o, como era lo habitual, se utilizara el casete con impulsos audibles para que el proyeccionista supiera en qué momento debía cambiar la imagen. ${ }^{15}$

Entre las carpetas estaba Destituidos, que contenía la funda con diapositivas y el guion, no así el casete con la banda sonora correspondiente. Las diapositivas, tras aplicar un procedimiento de limpieza e inspección, fueron digitalizadas en el LAPA para generar una nueva versión de este audiovisual. ${ }^{16}$ El audio se extrajo del VHS y el montaje se realizó tomando como referencia la secuencia del registro en video ya que, si bien en las fundas el orden de las imágenes era distinto, se pretendió respetar la intención con la cual CEMA había filmado el audiovisual. En el resultado obtenido resalta la ya mencionada calidad de la imagen, la nitidez y definición del color que contrastan con las imágenes mal encuadradas o descoloridas obtenidas tras la digitalización de la cinta VHS (Imagen 4 y 5). Este proceso de migración de un soporte a otro da cuenta de la importancia de conservar los originales, ya que la calidad de la imagen que es posible ver hoy en el archivo digital de Destituidos se debe a la estabilidad del

\footnotetext{
${ }^{15}$ Es posible ver un listado completo de las carpetas con diapomontajes en la base de datos del Lapa-AGUUdelar, en el siguiente enlace: https://archivosdocumentales.udelar.edu.uy/index.php/aih-lapa-ai-cema-02

${ }^{16}$ Se trató de una tarea realizada junto a Paolo Venosa, recuperada y editada por el Laboratorio de preservación Audiovisual del AGU (Lapa-AGU-Udelar) y es la versión disponible en el ya citado canal de Youtube.
} 
tipo documental que implica la diapositiva y su correspondiente proceso fotoquímico.
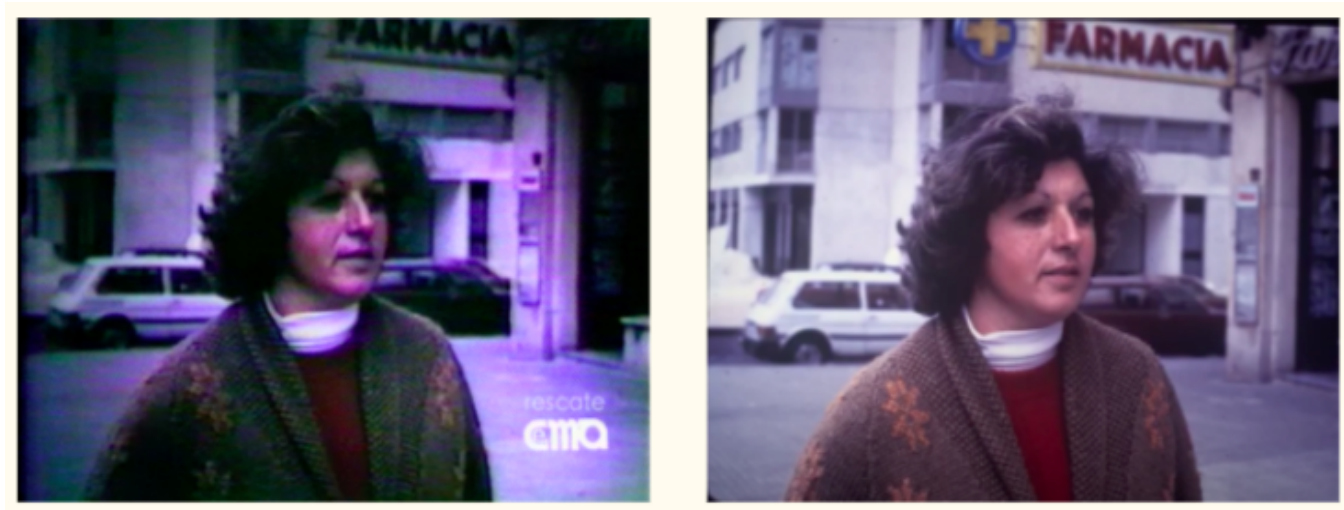

Imagen 4 y 5: Comparación de una captura de pantalla del VHS (a la izquierda) y la imagen fotografiada de la diapositiva original del diapomontaje Destituidos (CEMA, 1984). | En línea: https://www.youtube.com/watch?v=7NfTPV80Whs

A finales de 1980 parte del equipo de Imágenes organizó una proyección especialmente para que La gesta de una conciencia fuera capturada en video (en casete U-matic) (comunicación personal con D. Márquez, setiembre 2021). La posibilidad de acceder al objeto digital de este audiovisual fue posible gracias a un proyecto integral de digitalización del archivo de Imágenes compuesto por casetes U-matic y Betacam. ${ }^{17}$ Ambas situaciones, tanto sea por la posibilidad de migrar un VHS como un U-matic, dan cuenta de la importancia de atender los distintos pasajes tecnológicos $\mathrm{y}$, en particular, de la relevancia de contar con equipos que permitieran reproducir ambos tipos de cinta magnética, pues la pronta obsolescencia puede volver inaccesibles valiosos documentos audiovisuales.

\section{Reflexiones finales}

Como se vio a lo largo de este artículo, la forma que existe actualmente de acceder a los contenidos de los diaporamas es viable porque fueron primero grabados con cámaras de video y porque después hubo

\footnotetext{
${ }^{17}$ La propuesta presentada por Mario Jacob en 2019 contó con financiamiento de la Dirección Nacional del Cine y el Audiovisual (ICAU). La migración a digital de todo el archivo de Imágenes en formato U-matic y Betacam fue concretada por Daniel Márquez. Es posible ver toda la producción en el siguiente canal de Youtube: https://www.youtube.com/c/ProductoraIMAGENES
} 
proyectos para migrar a digital esos registros. ${ }^{18}$ De otra forma, si se contara únicamente con los originales, sólo sería posible componer una aproximación del material mirando las diapositivas y escuchando el audio, en caso de que estuviera digitalizado o se contara con equipos en buen estado que permitieran reproducir cintas de casete. De lo contrario, en caso de existir un guion, se podría saber el contenido de la locución, pero se perdería el entorno sonoro, la musicalización o los efectos de sonido utilizados en la banda de audio. La posibilidad de visionar los materiales y comprender sus formas de producción permite abordar algunas características particulares de un caso y otro. Para empezar, vale destacar que se trató de dos tipos diferentes de producción, uno como un claro trabajo por encargo y el otro elaborado como material para promover el diálogo y el intercambio crítico sobre un determinado asunto de actualidad del país. Y también difiere en los estilos: La gesta de una conciencia, en contraposición con Destituidos, fue un diapomontaje pensado como si se tratara de cine. Tal como recuerda Mario Jacob, "la cabeza con la que hicimos ese trabajo fue con la cabeza de gente que había hecho cine y sobre todo con conceptos de edición cinematográfica” (comunicación personal, M. Jacob, 2015). Esta afirmación resulta relevante ya que el pasado como realizadores cinematográficos podría explicar la diferencia en la experiencia de visionado que el público experimenta tras esta compleja proyección con diapositivas. Por su parte los integrantes del CEMA no habían tenido formación ni experiencia previa en producción audiovisual sostenida como los integrantes de Imágenes. ${ }^{19}$

En cuanto a los espacios de recepción vale precisar que en el caso de $L a$ gesta de una conciencia se trató de un documental informativo cuya observación implicaba para los espectadores acercarse a un determinado contexto histórico del país en el cual surgieron las instituciones involucradas, el sindicato de medicina, el gremio estudiantil y el sanatorio. En cambio, Destituidos fue una pieza contemporánea a los sucesos por los que atravesaba el país, por lo tanto, su presentación tenía previsto un posterior intercambio entre los asistentes.

En relación a la puesta en escena, a diferencia del gran despliegue que implicaba la exhibición de La gesta de una conciencia, Destituidos

\footnotetext{
${ }^{18}$ Para el caso de La gesta de una conciencia su migración a digital fue posible en el marco de un proyecto financiado por la Dirección Nacional del cine y el Audiovisual del Uruguay (ICAU)

${ }^{19}$ Interesa hacer la salvedad de la experiencia con la película Super $8 \mathrm{~mm}$ de Eduardo Casanova como integrante de CINECO. Para ampliar información sobre este colectivo ver Keldjian y Tadeo Fuica (2020).
} 
requería únicamente de una pared o una pantalla lisa en la cual pudieran verse una a una las imágenes y un equipo de sonido. Esta situación facilitaba su difusión en una amplia variedad de espacios ya que tampoco requería destrezas ni conocimientos especializados por parte del proyeccionista. Otro aspecto a destacar en los relatos sobre las experiencias vinculadas a la exhibición de los diapomontajes es la situación del carácter performativo del acto de proyección, dado que muy raramente se asistía al mismo visionado, tanto por el resultado final del audiovisual que se exhibía, como el contexto o la discusión que tenía lugar una vez finalizada la proyección.

En todo caso, para el CEMA y para Imágenes, el diaporama fue la herramienta de transición audiovisual entre la realización de películas de emulsión fotoquímica, hacia el uso del video, es decir, las cintas magnéticas. En el caso de los jóvenes integrantes del CEMA, mayoritariamente por el uso de rollos fotográficos y una única experiencia en Super $8 \mathrm{~mm}$, y en el de los integrantes de Imágenes, la película $16 \mathrm{~mm} .{ }^{20} \mathrm{El}$ advenimiento del video significó el puntapié inicial de la globalización comunicacional. Al adoptar la tecnología video, que según la opinión de los integrantes del CEMA era un medio más "democratizador" (Balás 2016b, 71), con el tiempo, a medida que la democracia se instalaba en el país y los apoyos financieros del exterior se iban retirando, debieron buscar alternativas para sostener sus empresas. Necesariamente tuvieron que adaptarse a las "reglas de juego" de los formatos y las normas que establecían los canales europeos para poder entrar en sus mercados. ${ }^{21}$ En términos prácticos el video permitía tener al instante el material para visionar y, en sentido económico, era más simple la obtención de copias que facilitaba su distribución y por lo tanto el acceso a personas más allá de fronteras. El traslado de un casete de video se contraponía a la dificultad que planteaban las pesadas latas de material en cinta fílmica de $16 \mathrm{~mm}$ o 35 $\mathrm{mm}$. Por su parte, la producción de video trajo aparejado el surgimiento de los Video Clubs, que modificó el hábito de ver películas en la comodidad del hogar. Se podría establecer que la facilidad para acceder

\footnotetext{
${ }^{20}$ CEMA utilizó el soporte fotoquímico de pase Super $8 \mathrm{~mm}$ para un registro solicitado por la Federación Uruguaya de Cooperativas de Vivienda de Ayuda Mutua (FUCVAM), se trató de la inauguración de la cooperativa COVICENOVA. Vease Covicenova: un techo de todos", Eduardo Casanova, 1984, 13' (tarjetas con la producción del CEMA, archivo privado de Miguel Ángel Olivera).

${ }^{21}$ Para ampliar sobre las modalidades que las productoras, en particular CEMA, debieron adoptar para sostener la productora ver Balás (2020).
} 
de manera doméstica a los materiales audiovisuales inició con este cambio de soporte. ${ }^{22}$

La posibilidad de contar con los archivos digitales de estos audiovisuales a un click permite acercarse a nuestra historia reciente y producir investigaciones y análisis con distintas perspectivas. Pero para que ello sea posible es preciso poner atención en la conservación de los documentos originales y los equipamientos que permiten su reproducción. En este sentido es preciso valorar los procesos integrales de estos archivos que permitieron acceder a los registros de los casos mencionados. De este modo fue posible desplegar otras interpretaciones y poner en diálogo los contextos políticos con las formas de comunicar según las tecnologías disponibles. Tomar contacto con la materialidad de los soportes, acceder a sus texturas, permite recuperar sus particulares contextos de uso y exhibición en su tiempo y espacio, comprender sus posibilidades y sus limitaciones.

\section{Referencias}

Balás, Mariel. 2020. "Producción del video regional para el mercado global en los noventa. El caso de "La esperanza incierta" (1991)." Encuentros Latinoamericanos 4(2): 214-238. Acceso el 25 de junio de https://ojs.fhce.edu.uy/index.php/enclat/article/view/880. . 2018. “¿Reconocer o conocer a través de las pantallas? El CEMA y las estrategias para llegar más allá de fronteras”. En: Uruguay se filma. Prácticas documentales (1920-1990), editado por Georgina Torello, 195-217. Montevideo: Irrupciones grupo editor.

———. 2016. "Centro de Medios Audiovisuales de Uruguay. Cuando el video empieza a ser creación, arte, información y registro”. En:

\footnotetext{
${ }^{22} \mathrm{Si}$ bien no es el objetivo de este artículo abordar lo que sucede hoy con la producción digital, cabe tener en cuenta que, desde la aparición del formato magnético para la producción audiovisual, la tecnología no se ha detenido en la búsqueda por continuar facilitando el acceso a herramientas que permitan que cada persona pueda convertirse en productor de sus propias obras audiovisuales. Incluso capaz de difundir y hasta "viralizar" algunas imágenes que llegan y se vuelven a compartir de manera casi "ilimitada" a través de pantallas domésticas y personales de las computadoras, tabletas, celulares, transformadas en combinaciones binarias de ceros y unos, cuya tangibilidad es asombrosamente inasible. Al parecer, nuestra contemporaneidad nos mantiene alejados de la constatación de lo efímero del soporte digital. Resulta difícil pensar en la documentación a futuro de situaciones que hoy, y en particular a partir de la pandemia de COVID - 19, nos resultan cotidianas como las reuniones y los eventos a través de plataformas virtuales. Por lo pronto, la preservación y reconstrucción de nuestra contemporaneidad en el futuro será un desafío que atender.
} 
Memorias y representaciones en el cine chileno y latinoamericano, coordinado por Mónica Villarroel, 69-77. Santiago de Chile: LOM ediciones.

Balás, Mariel y Tadeo Fuica, Beatriz. 2020. "Archivo del CEMA: reflexiones sobre su constitución, y sus usos pasados, presentes y futuros". En: Transiciones de lo real. Transformaciones políticas, estéticas y tecnológicas en el documental de Argentina, Chile y Uruguay, editado por Paola Margulis, 299-320. Buenos Aires: Libraria.

Caetano, Gerardo y Rilla, José. 1998. Breve historia de la dictadura. Montevideo: EBO.

Fernández Puig, Macarena. 2015. "Audiovisual con diapositivas, una alternativa para crear imagen-movimiento". Revista 33 cines, tercera época, número 2. Acceso el 23 de octubre de 2019. http://33cines.uy/audiovisual-con-diapositivas-una-alternativapara-crear-imagen-movimiento-1975-1983/.

Gaudreault, André y Marion, Philippe. 2005. "A Medium is Always Born Twice”. Early Popular Visual Culture 3(1): 3-15.

González Dambrauskas, Santiago. 2020. La producción audiovisual uruguaya no publicitaria entre los años 1985 y 2001: estudio de caso de la productora Imágenes. Tesis de maestría. Montevideo: Universidad de la República (Uruguay), Facultad de Información y Comunicación.

Jacob, Lucía. 1997. C3M: una experiencia singular. Montevideo: Cinemateca Uruguaya.

Keldjian, Julieta y Tadeo Fuica, Beatriz. 2020. "Documentales uruguayos de los ochenta: La resistencia entre el súper-8 y el video". En: Transiciones de lo real. Transformaciones políticas, estéticas y tecnológicas en el documental de Argentina, Chile y Uruguay, editado por Paola Margulis, 229-252.Buenos Aires: Libraria.

Lacruz, Cecilia. 2016. "La comezón por el intercambio". En: Las rupturas del 68 en el cine de América Latina, editado por Mariano Mestman, 311-351. Buenos Aires: Akal.

Liñero, Germán. 2010. Apuntes para una historia del video en Chile. Santiago: Ocho libro editores. 
Margulis, Paola. 2020. Transiciones de lo real. Transformaciones políticas, estéticas y tecnológicas en el documental de Argentina, Chile y Uruguay. Buenos Aires: Libraria.

Palazón, Alfonso. 2001. “Diaporama: percepción audiovisual”. Revista Universo Fotográfico III(4). Acceso 23 de mayo de 2019. http://webs.ucm.es/info/univfoto/num4/pdf/4palazon.pdf.

Tadeo Fuica, Beatriz. 2017. Uruguayan Cinema, 1960-2010. Text, Materiality, Archive. Woodbridge: Támesis.

Tadeo Fuica, Beatriz y Balás, Mariel. 2016. CEMA: archivo, video y restauración democrática. Montevideo: FIC-UDELAR-ICAU.

Torello, Georgina. 2018. La conquista del espacio. Cine silente uruguayo (1915-1932). Montevideo: Yaugurú.

Villaça, Mariana. 2012. "El cine y el avance autoritario en Uruguay. El 'combativismo' de la Cinemateca del Tercer Mundo". Revista Contemporánea. Historia y problemas del Siglo XX 3(3): 243-264.

\section{Diapomontagens: Audiovisuais de transição no Uruguai de meados dos anos 1980}

RESUMO A intenção deste artigo é abordar o uso da diapomontagem como uma tecnologia de transição entre a fita fotoquímica e a fita de vídeo. Para tanto, serão colocadas em diálogo duas produções de meados da década de 1980, que correspondem a duas produtoras uruguaias contemporâneas. São elas: Destituidos (1984), do Centro de Medios Audiovisuales (CEMA), e La gesta de una conciencia (1985), da produtora Imágenes. O tipo de audiovisual aqui apresentado como meio de expressão comunicacional e cultural foi amplamente utilizado durante a ditadura uruguaia, ocorrida entre 1973 e 1985, e tem sido pouco estudado. A partir de uma abordagem à técnica do slideshow e da combinação dos suportes que tornam possível a experiência audiovisual (fotoquímica, no caso do diapositivo, e magnética, no caso da cassete áudio), serão analisadas a produção de conteúdos, a montagem e a posta em cena, num caso e no outro.

PALAVRAS-CHAVE Diapomontagem; transição; arquivo; vídeo; audiovisual uruguaio; diapositivos. 


\title{
Slide Montage as Transition Audiovisuals in mid-1980s Uruguay
}

\begin{abstract}
The intention of this article is to address the use of slide montage as a transition technology between photochemical tape and videotape. To accomplish this, two productions from the mid-1980s that correspond to two contemporary Uruguayan production companies will be put into dialogue. These are Destituidos (1984) by the Centro de Medios Audiovisuales (CEMA) and La gesta de una conciencia (1985) by the production company Imágenes. The type of audiovisual presented here as a means of communication and cultural expression was widely used during the Uruguayan dictatorship that took place between 1973 and 1985. It is a type of audiovisual production that has been little researched. Starting from the technique of the slideshow and the combination of the supports that make the audiovisual experience possible (photochemical of the slide and magnetic of the audio tape), we will analyse the production of contents, the montage and the staging in one case and another.
\end{abstract}

KEYWORDS Slide montage; transition; archive; video; Uruguayan audiovisual; slides.

Recebido a 16-07-2021. Aceite para publicação a 29-10-2021.

aniki A Pesquisa Histórica no Cinema Latino-americano | Historical Research in Latin-American Cinema 